BULLETIN Bulletin hispanique

HISPANIQUE Université Michel de Montaigne Bordeaux

121-1 | 2019

La épica en el mundo hispánico (Siglo de Oro)

\title{
Luis Landero, Juegos de la edad tardía [1989], edición de Elvire GOMEZ-VIDAL BERNARD
}

Madrid: Cátedra, col. Letras Hispánicas, 2018

\section{Geneviève Champeau}

\section{(2) OpenEdition}

Journals

Edición electrónica

URL: https://journals.openedition.org/bulletinhispanique/8273

DOI: $10.4000 /$ bulletinhispanique.8273

ISSN: 1775-3821

Editor

Presses universitaires de Bordeaux

Edición impresa

Fecha de publicación: 24 junio 2019

Paginación: 394-398

ISBN: 979-10-300-0363-5

ISSN: 0007-4640

Referencia electrónica

Geneviève Champeau, «Luis Landero, Juegos de la edad tardía [1989], edición de Elvire GOMEZ-VIDAL BERNARD», Bulletin hispanique [En línea], 121-1 | 2019, Publicado el 24 junio 2019, consultado el 05 enero 2023. URL: http://journals.openedition.org/bulletinhispanique/8273 ; DOI: https://doi.org/10.4000/ bulletinhispanique.8273

Este documento fue generado automáticamente el 5 enero 2023.

All rights reserved 


\section{Luis Landero, Juegos de la edad tardía [1989], edición de Elvire GOMEZ-VIDAL}

\section{BERNARD}

Madrid: Cátedra, col. Letras Hispánicas, 2018

\section{Geneviève Champeau}

\section{REFERENCIA}

Luis Landero, Juegos de la edad tardía [1989], edición de Elvire GOMEZ-VIDAL BERNARD. Madrid: Cátedra, col. Letras Hispánicas, 2018, 772 p.

1 Luis Landero publicaba en 1989 su primera novela que tuvo inmediatamente una acogida muy favorable -27 ediciones durante los diez años- y fue galardonada por varios premios como el de la Crítica y el Premio Nacional de Literatura. La edición crítica que, en 2018, le dedica Cátedra, en su colección Letras Hispánicas, es un paso más hacia su reconocimiento, en el campo de las letras, como clásico contemporáneo.

2 Esta edición, a cargo de Elvire Gomez-Vidal Bernard, catedrática emérita en la universidad Bordeaux Montaigne, presenta un destacado interés didáctico al ofrecer, en un estilo fluido y ameno, varios estudios en uno. Además de una extensa bibliografía que abarca la totalidad de la obra del escritor, consta de una introducción de 99 páginas y de una densa red de notas a pie de página excepcionalmente numerosas (662 en total) y copiosas, que pueden alcanzar una página, incluso excepcionalmente algo más.

3 La edición crítica que publica Cátedra aúna el rigor y la erudición que exige este género universitario con la fruición que experimenta manifiestamente quien redactó el aparato crítico esforzándose por comunicar al lector el propio placer de leer y comentar ficciones.

4 Una extensa introducción ofrece una presentación sintética de la novela que, después de unas cuantas consideraciones contextuales, hace hincapié en la estructura 
laberíntica de una obra que mimetiza en su composición las vivencias del protagonista, Gregorio Olías, cuya inadaptación a la realidad circundante le lleva a extraviarse en sucesivos laberintos vitales y verbales que él mismo va fraguando por obra de la pulsión ficcional que lo anima; una pulsión que lo empuja a inventar sartas constantemente renovadas de embustes, de patrañas que el narrador calificará de farsas. Dentro del laberinto textual del que también participa la instancia narradora al multiplicar los lances que hacen rebotar constantemente la acción, conformemente a la tradición de los folletines populares -Juegos de la edad tardía contribuye a la rehabilitación de la acción y del personaje, como unos años antes, La verdad sobre el caso Savolta de Eduardo Mendoza (1975)-, el análisis tira del hilo de la estructura temporal, disimulada por la frondosidad el relato y apenas perceptible en notaciones dispersas, aunque organiza rigurosamente la novela en función de una fecha, el 4 de octubre. En efecto, esta fecha divide en dos el relato, separando un bucle rememorativo que abarca el pasado del personaje del giro radical que provoca, a partir de esta fecha, la irrupción en la ciudad en la que vive Gregorio Olías del interlocutor destinatario de sus embustes, el viajante Gil, irrupción que amenaza con arruinar la patraña y obliga al protagonista a inventar nuevas mentiras que no impedirán su derrota final (p. 19-34).

Destaca, por otra parte, la dimensión eminentemente intertextual de la novela de Landero que echa mano de una cultura de manuales escolares, en consonancia con la formación del protagonista y de fácil identificación por el lector. Elvire Gomez-Vidal Bernard califica por ello la novela de "antológica" (p. 75). La intertextualidad se vuelve motor de la escritura al diversificar las fuentes textuales en "divertida mezcolanza" de corte posmoderno que autoriza una interpretación literal del término 'farsa' en el sentido etimológico de relleno (p. 71). En su doble vertiente de lectura y reescritura, el intertexto arroja luz sobre la temática central de Juegos de la edad tardía, la dinámica de la creación y de la recepción. Paralelamente, en la diégesis, el papel de la recepción en la motivación de la creación queda plasmado en el personaje de Gil, destinatario de las patrañas de Gregorio, quien impulsa a Gregorio a mentir por sus preguntas insistentes y su irrupción amenazante en la ciudad (p. 57).

6 Cabe destacar por otra parte la adecuación entre la fascinación del protagonista, Gregorio Olías, por la magia de las palabras (p. 202-205) y la metodología de Elvire Gomez-Vidal Bernard, atenta a las potencialidades de los significantes, conformemente a las enseñanzas de Nadine Ly, quien teorizó la "literalidad" como método de análisis textual (ver nota 190).

7 La autora de esta reseña queda menos convencida por la "denuncia política por las vías de la irrisión burlesca" (p. 47-53). Si bien la sátira de la mediocridad de la posguerra que ilustra la Academia nocturna es convincente, la respuesta vital de Gregorio Olías ante una realidad decepcionante no es la resistencia ni la rebelión sino la reiterada evasión hacia mundos imaginarios. La referencialidad histórica, las cuestiones sociales y políticas permanecen borrosas y anecdóticas. Los episodios relativos a la represión son frutos de la imaginación del protagonista, de su voluntad de no ser desenmascarado y de la intención autorial de multiplicar los lances a cual más estrafalario. ¿Qué credibilidad Cabe atribuir a una sátira que se limitaría a manejar tópicos? En cuanto al episodio de la visita de Franco que se resume en un destello de luces y una caravana de coches negros (p. 531), bien podría ser una alusión humorística a la película de Berlanga Bienvenido Mr Marshall (1953) en la cual un pequeño pueblo de los alrededores de Madrid se engalana y disfraza, confiando en la visita de dignitarios americanos de los que 
esperan el maná del "plan Marshall", y queda defraudado ante el paso de la comitiva que cruza el pueblo sin pararse y se pierde en una nube de polvo.

Escribía, al empezar esta reseña, que en este volumen caben varios estudios. Justifica tal afirmación la peculiaridad de las notas a pie de página que rebasan las funciones que se les suele atribuir en las ediciones críticas.

9 Cumplen, por una parte, con una función de esclarecimiento puntual de ciertas oscuridades del relato, de enunciados alusivos o misteriosos. En una novela eminentemente intertextual, identifican además los hipotextos, invirtiendo en ello una notable y diversificada cultura literaria. Cabe observar que esta clase de notas no se limita a explicitar la referencia intertextual sino que cuida de explicar cómo se integra en el relato y qué efectos de sentido genera (cf. como botón de muestra, las notas 134 a $137,148,155)$. Otras veces, la profesora establece juiciosas comparaciones de su propia cosecha con otras obras: las mitologías greco-latinas y la Biblia, las obras de Shakespeare, Proust, Borges, Octavio Paz, Pablo Neruda, Flaubert y otras muchas, muy diversas, destacando dos hipotextos decisivos, La metamorfosis de Kafka y más aún El Quijote de Cervantes.

Otras notas a pie de página son descriptivas. Ilustran las consideraciones sintéticas presentadas en la introducción, aclaran, como se ha dicho, la estructura compleja de la obra estableciendo vínculos entre episodios lejanos, subrayando particularmente las referencias temporales, hitos en la progresión del relato, recalcando los mecanismos del suspense -apuntan, por ejemplo, las diversas irrupciones del "diablo" que solo se aclaran al final de la novela- o las ocurrencias de una metáfora clave, como la de "laberinto".

11 A ello se añaden auténticos comentarios de texto, ejercicio en el que destaca la autora de esta edición por su fineza, perspicacia analítica y la productividad de su método heurístico. A partir de este momento, las notas a pie de página dejan de ser informativas para adentrarse en la interpretación. La labor interpretativa, atenta al carácter lúdico de la creación literaria, echa a menudo mano de la etimología que atribuye a las palabras significaciones distintas de las habituales y establece redes semánticas insólitas que va reconstituyendo el lector. También se vale de asociaciones, sugeridas por los significantes, que la profesora aplica preferentemente a la onomástica, a partir del principio según el cual en literatura, a diferencia del uso habitual del lenguaje, los nombres no son arbitrarios y determinan el destino del personaje (cf. el patronímico Olías en la nota 358, Faroni en las notas 108 y 185, 217, 299, Gil en la larga nota 170). Saca aun provecho de la simbología de las cifras, tanto el cuatro como el dos, el ocho como el diez (cf. por ejemplo la notas 347, 354, 365, 549), particularmente en relación con el mes de octubre -el eje temporal de la novela es, recordémoslo, el 4 de octubre-, un mes ambivalente al proceder etimológicamente del ocho aunque es el décimo mes del año. Una ambivalencia generadora de otras muchas en una novela en la que la verdad del protagonista es la mentira, en la que lo burlesco va a la par de lo trágico (cf. las notas 343, 482). Que el lector quede o no del todo convencido por este juego interpretativo, que pueda o no estimarlo en algunos casos excesivo, el ejercicio no deja de ser siempre estimulante e invita a una lectura que, sin ser arbitraria -el texto no permite cualquier interpretación-, no se atenga a las significaciones evidentes y desentrañe las redes semánticas que va creando la materialidad del lenguaje. 

burlesco de unos personajes ambivalentes, actores de una tragicomedia, seres mediocres, reflejos de la mediocridad circundante, pero también trágicos si se consideran las metas inalcanzables que se fijan ("el afán"). Frente a los héroes clásicos, Elvire Gomez-Vidal Bernard destaca una épica de lo cotidiano que acaba reivindicando lo mediocre (p. 90). La vertiente interpretativa incluye, al filo de las páginas, los recursos de la comicidad y de la farsa burlesca, que puede incluir lo soez, en la tradición carnavalesca ya presente en la obra de Rabelais y analizada por Bajtín al que se refieren a menudo las notas (en particular la nota 482 ).

13 En fin, el aparato crítico incluye consideraciones teóricas sobre la opción hermenéutica adoptada. Expone en sucesivas pinceladas un método de análisis textual heredero de los aportes del estructuralismo y la lingüística, fundado en la coherencia del texto-tapiz, "sistema semántico y semiótico cerrado, organismo autónomo, de una irreductible peculiaridad, en que todos los componentes son solidarios y que erige sus propias reglas de funcionamiento. Lo cual no impide, al contrario, el que también sea 'obra abierta', en tanto representación y cuestionamiento de la realidad extratextual, en tanto integrador de textos anteriores, en tanto texto que favorece un amplio espectro de lecturas interpretativas" (nota 365). La autora de la edición reivindica la pertinencia de una labor interpretativa no sujeta a la intención del autor: "dudo de que un narrador lo planee todo; de lo que sí estoy segura es de que un gran escritor intuye y edifica sin hacerlo consciente, sin premeditación, una serie de redes de significación que estructuran el universo novelesco creando un sistema semántico coherente y único en el que cada elemento textual, por muy nimio que parezca, es solidario de los demás" (nota 567).

14 Esta edición crítica de Juegos de la edad tardía puede acompañar y enriquecer la lectura de cualquier aficionado a la literatura. Contiene un perspicaz, sugerente y abarcador análisis de la novela, repartido entre introducción y notas a pie de página, que puede servir de introducción a la obra de Landero gracias a las referencias que en ellas se hacen a novelas posteriores del mismo autor. En su parti-pris de atención a la letra del texto, ofrece un ejemplo de análisis textual fructífero a la hora de adentrarse en la peculiaridad de los procesos de la creación y de la comunicación literarias.

\section{AUTORES}

\section{GENEVIÈVE CHAMPEAU}

Université Bordeaux Montaigne Professeur émérite 